This item was submitted to Loughborough's Research Repository by the author.

Items in Figshare are protected by copyright, with all rights reserved, unless otherwise indicated.

\title{
Ageing and chronic illness in language and sexuality
}

\section{PLEASE CITE THE PUBLISHED VERSION}

http://doi.org/10.1093/oxfordhb/9780190212926.013.35

\section{PUBLISHER}

(C) Oxford University Press (OUP)

\section{VERSION}

AM (Accepted Manuscript)

\section{LICENCE}

CC BY-NC-ND 4.0

\section{REPOSITORY RECORD}

Peel, Elizabeth, and Sonja J. Ellis. 2019. "Ageing and Chronic Illness in Language and Sexuality". figshare. https://hdl.handle.net/2134/27453. 
Peel, E. \& Ellis, S.J. (forthcoming, 2018) Ageing and Chronic Illness in Language and 1 Sexuality. In K. Hall \& R. Barrett (Eds.) The Oxford Handbook of Language and Sexuality. Ageing and Chronic Illness in Language and Sexuality

Oxford: Oxford University Press.

\author{
Elizabeth Peel \\ Loughborough University, UK \\ Sonja J. Ellis \\ Australian Catholic University
}

\begin{abstract}
An ageing demographic in Western societies as well as globally has made public health issues, such as dementias, subject to hyperbolic metaphor such as "tsunami" and "time bomb." This chapter reviews the state of knowledge regarding language, sexualities, ageing, and chronic illness. In particular, we focus on discursive research from across the social sciences that furthers understandings of older people's lives and experiences. We highlight research that has focused on ageism and chronic conditions impacting older people (specifically, dementia and type 2 diabetes), including empirical research on these conditions, and on manifestations of heterosexism and heteronormativity in these contexts. Using illustrative examples that emphasize the intersection of discourse and issues that relate to ageing, we foreground this area as an important element of language and sexuality scholarship. Last, we indicate future directions for the development of research focusing on these topics.
\end{abstract}

Key words: ageing; chronic illness; conversation analysis; dementia; discourse; LGBTQ 
Peel, E. \& Ellis, S.J. (forthcoming, 2018) Ageing and Chronic Illness in Language and

\section{DEMENTIA, METAPHOR, AND SEXUALITY}

Illness is the night-side of life, a more onerous citizenship. Everyone who is born holds dual citizenship, in the kingdom of the well and in the kingdom of the sick. Although we all prefer to see only the good passport, sooner or later each of us is obliged, at least for a spell, to identify ourselves as citizens of that other place. [...] My subject is not physical illness itself but the uses of illness as a figure or metaphor. My point is that illness is not a metaphor, and that the most truthful way of regarding illness - and the healthiest way of being ill - is one most purified of, most resistant to, metaphoric thinking. Yet it is hardly possible to take up one's residences in the kingdom of the ill unprejudiced by the lurid metaphors with which is has been landscaped (Sontag 1978: 3, emphasis in original).

As Susan Sontag (1978) highlighted in her classic book Illness as Metaphor, illness is inseparable from the language and metaphor through which we understand the experience. What is powerful about Sontag's analysis, though not without its critics, is the emphasis squarely placed on language in the context of chronic illness. Sontag's focus was specifically on cancer and tuberculosis - preeminent illnesses of modern and early modern times respectively. She draws a sharp distinction between the problematic "lurid metaphors" and the actual lived experience of illness - which, as she indicates in the opening quotation of this chapter, should be unsullied by the language through which we understand it.

Our focus in this chapter departs from Sontag in a number of key ways. First, we take a social constructionist - or at least a critical realist - stance (rather than the implied realist stance in the quotation above) to explore how language impacts chronic illness and ageing. In other words, rather than seeing metaphor as controlling as Sontag did, and thus problematic for those living with illness, we would see metaphor and language as foundational to the 
Peel, E. \& Ellis, S.J. (forthcoming, 2018) Ageing and Chronic Illness in Language and

Sexuality. In K. Hall \& R. Barrett (Eds.) The Oxford Handbook of Language and Sexuality. Oxford: Oxford University Press. ways in which illness is understood. Rather than seek to strip away metaphor to enable the 'real' illness to be lived, then, the emphasis is on analyzing the different ways and contexts in which discourse and metaphor shape understandings of illness. If tuberculosis and cancer were the 'master illnesses' of early modernity and modernity then, arguably, dementias occupy that status in post-modernity. However, merely labelling particularly illnesses in such terms does little to tease out variation, or indeed contestation, in metaphor and language use with regard to chronic illness. Second, we take sexuality as a critical lens in interrogating discursive and communicative approaches to health and illness. Third, we bring to the fore two different chronic illnesses that constitute significant contemporary public health issues for older people: dementia and type 2 diabetes.

The chapter considers ageing and chronic illness in these interconnected ways for three similarly interconnected reasons. The first, and most obvious, is that in Western societies, and globally, there is an ageing demographic (WHO 2015). That is, there are increasing numbers of older people in the population; in many cases exceeding the numbers of younger people in the population. As chronic health problems disproportionately impact people as they age, it is important to understand the interface between ageing and chronic illness. Secondly, it would be reasonable to suggest that language and sexualities scholarship has not, historically, taken ageing and chronic illness as mainstays of analytic focus (cf. Peel and Harding 2016). Finally, in offering this focus, we not only suggest that issues connected to ageing and chronic illness offer fertile ground for language and sexuality researchers, but also tease out some of the salient themes in how such scholarship may wish to progress, especially with regard to non-heterosexuality or heteronormative sexualities.

The construction, prevalence, and context of use of metaphor are significant when considering language and ageing - they provide "ways to perceive and experience much of the world" (Lakoff \& Johnson, 2003: 239). To take a recent example, Zsofia Demjen, Elena 
Peel, E. \& Ellis, S.J. (forthcoming, 2018) Ageing and Chronic Illness in Language and

Semino, and Veronika Koller (2016) have suggested, based on interviews with UK palliative healthcare professionals, that the difference between a 'good' and a 'bad' death is partly communicated through the frequency of contrasting metaphors ("peacefulness" and “openness" for a 'good death' versus "struggle” for a 'bad death'). They demonstrate how metaphors are used to justify and evaluate deaths and those dying, and thereby promote a particular framing of what constitutes a good death. This sits in stark contrast to Sontag's call to purify illness of metaphoric thinking.

More broadly, both public health and media discourse about ageing and certain chronic conditions such as dementia are replete with hyperbolic metaphor such as "tsunami" and demographic “time bomb” (Peel 2014). Peel’s (2014) research analyzed British newspaper media coverage on dementia and Alzheimer's disease across 350 articles published in 2010 to 2011, finding a 'panic-blame' framework in evidence. On the one hand, dementia was conveyed in catastrophic terms and communicated a public health panic (a "tsunami"; "worse than death"; "Alzheimer's epidemic"). On the other hand, and somewhat paradoxically, there was much evidence of a dementia 'prevention' discourse that incorporated individual responsibility and (potentially) blame towards the person for developing the condition. There was an emphasis on lifestyle recommendations to "stave off" the condition within the prevention discourse, some of which were directly contradictory (e.g., "Fatties 80\% more likely to develop Alzheimer's," "Stick to a high-fat diet to avoid Alzheimer's") (Peel 2014: 894).

Health discourse frequently invokes military metaphors (e.g. 'war', 'fight', 'battle') in conjunction with discussions around illness and disease. Military metaphors, while dating back to at least the $17^{\text {th }}$ century as descriptors for illness generally (Lane, McLachlan, and Philip 2013), have only relatively recently been used in communication about dementia. Lane, McLachlan and Philip (2013), in discussing positive and negative aspects of military 
Peel, E. \& Ellis, S.J. (forthcoming, 2018) Ageing and Chronic Illness in Language and

Sexuality. In K. Hall \& R. Barrett (Eds.) The Oxford Handbook of Language and Sexuality. Oxford: Oxford University Press. metaphors, draw our attention to their use in the dementia context. They note that public health, and the use by charities of military metaphors - for instance the UK's Alzheimer's Society strapline "leading the fight against dementia" - has likely contributed to the raised profile of dementia. They caution, however, that:

[A]t an individual level a chronic illness such as dementia is arguably not usefully conceived as a battle. First, no curative treatments are available as "arsenal".

Secondly, many people with dementia are older and face other medical conditions or disability. These people may not be in a position to 'fight'. [...] Military metaphors focus on the immediate 'fight' and may impede conversations about the future. Additionally, fighting metaphors may leave some individuals feeling they have 'lost' as the disease progresses [... and] from a broader perspective, focus on 'battling' dementia, may distract from discussion about how our communities best care for and support an increasing number of people and their families as the population ages (Lane, McLachlan \& Philip, 2013: 282-3).

In interview and focus group research with informal carers of people living with dementia in the UK, there is evidence of 'battling' discourse in a different sense. Ironically, rather than military metaphor being levelled at the disease, it was found that "many carers described the process of accessing health and social care services for the person they care for as a 'battle' or "fight"' (Peel and Harding 2014: 655). For example, in the words of James, a 47 year old ex-carer who was one of the focus group participants:

You're under immense strain caring for somebody who has, in effect, behavioural difficulties through no fault of their own and you're under that mental, emotional, physical effort and at the same time you're having to battle the system [...] you're 
Peel, E. \& Ellis, S.J. (forthcoming, 2018) Ageing and Chronic Illness in Language and 6 Sexuality. In K. Hall \& R. Barrett (Eds.) The Oxford Handbook of Language and Sexuality. Oxford: Oxford University Press. having to go to- it's like being in World War III, you'll go into one battle and another one starts. (Peel and Harding 2014: 656)

Therefore, we see here, while James stops short of describing "having to go to" war explicitly, he makes vivid and detailed use of military metaphor directed at "the system" of health and social care services that are ostensibly designed to enable and support people with dementia and their families.

Military metaphor can be levelled at many different targets. In other research, such as online survey data with LGBTQ people living with various chronic illnesses, the target appears to be cultural stereotypes: "[h]aving to battle the cultural stereotypes that queers (especially gay men) are supposed to be the fit, buff model of health, and that 'these things don't happen to us' has been a difficult mental barrier" (Black gay man, USA, diabetes, sleep apnea, quoted in Jowett and Peel 2009: 462). A key component in considering ageing and chronic illness through the dual lens of language and sexuality must, therefore, be our communities (Lane et al., 2013). Critical, in our view, are LGBTQ communities as they age and experience chronic illness, and how discourses applied to these communities intersect with other crucial axes of oppression and marginalization, such as gender, ethnicity, and (dis)ability.

With regard to dementia, there is increasing discursive space being made for understanding dementia as a gendered issue, with women being more affected than men (e.g., Erol, Brooker, and Peel 2015, 2016). And within this, there is now some recognition that lesbian and bisexual women, and LGBTQ people generally, are differentially impacted by a discursive landscape (and resultant policy and care contexts) predicated on hetero- and cisgender normativity (Peel and McDaid 2015; Semlyen, Brooke, and Peel submitted; Westwood 2014). For example, Rowena, an older lesbian cited in Knocker's (2013) study of LGB people's perspectives on ageing, describes the importance of linguistic and subcultural 
Peel, E. \& Ellis, S.J. (forthcoming, 2018) Ageing and Chronic Illness in Language and

recognition within care home contexts: “"[j] ust as it is important to have someone who speaks

English or the same language as you, so you can communicate, I need someone who can

'speak lesbian!' Our culture is different and we have different ways of doing things. It is a bit indefinable, but it is really important" (Knocker 2013: 11). In other words, discursive space results in actual space — or rather, actual recognition — that acts as a counter to the lack of visibility that often occurs in relation to LGBTQ ageing. ${ }^{1}$

This lack of visibility of LGBTQ ageing occurs on a number of planes, and is encapsulated in these two quotations "[t]he disappearance of older lesbians and gay men [and bisexual, trans and queer people] may seem somewhat analogous to a science fiction tale in which everyone over a given age suddenly vanishes as if to avoid tarnishing younger people" (Pugh 2002: 162; cited in Clarke, et al., 2010: 216); and “[i]nstitutions, they're very straight. My god I hope I don't have to go into a care home [...] It frightens me that I am just going to be invisible, a nobody, that I am just going to be lost" (May, age 64; quoted in Westwood 2014: 10). The first quote, taken from Stephen Pugh's observation about the gerontological literature, underscores the ageist discourse that has been identified in some parts of LGBTQ communities, most notably with regard to a 'youthist' gay male culture (cf. Tyler, et al., 2016). The second, taken from Sue Westwood's study of dementia concerns among lesbian and bisexual women, highlights the lack of recognition of older LGBTQ identities in care home settings, and how the heternormativity of these institutions is pervasive (cf. Phillips and Marks 2008). In the context of sexuality research in general the observation has been made that LGBT research is "in its infancy" (Sutherland, Rivers and Ward, 2012: 11), and as such is fertile ground for language and sexuality scholars to plough. In the following section, we consider discourses associated with physical change in ageing sexualities, before returning to discursive concerns in the context of sexuality and chronic illness. 
Peel, E. \& Ellis, S.J. (forthcoming, 2018) Ageing and Chronic Illness in Language and

\section{SEXUALITY AND AGEING}

"Healthy ageing," "successful ageing," "active ageing" - these are all expressions that are peppered through gerontological and public health discourse regarding ageing. In the UK, for example, following the National Service Framework established for Older People (Department of Health 2001), government rhetoric shifted towards the phrase "successful ageing." Although this rhetoric has been enthusiastically adopted by some fit, healthy, and socially engaged older people, the term (and its implied neo-liberal mandate to remain healthy in older age) has been subject to heavy critique (e.g., Marshall 2006) and belies the experiences of those with chronic or degenerative conditions.

In mainstream discourse, there is a widespread notion that older people are not sexually active and/or not interested in sex. ${ }^{2}$ Despite being a common perception, this is not borne out in the research literature. For example, an analysis of UK data (Lee, et al., 2015) indicates that many older people are sexually active well into their 70s and 80s. Furthermore, it is often societal and structural issues that prevent older people from being sexual rather than a lack of desire (cf. Phillips and Marks 2008). It has been argued that "inattention to sexuality is a key feature of ageism" (Ward et al., 2005: 51). The subjectification of older people as 'asexual' (Hinchliff and Gott 2016) is perpetuated by language and representations that construct (and promote) sexuality as being the domain of the young, healthy, and beautiful (see also Bucholtz and Hall this volume; Ramanathan this volume). Older bodies, especially older women's bodies, are not viewed as sexually appealing and therefore receive limited visibility. For example, in popular media, representations of young bodies typically comprise revealing nude shots, while the ageing body is concealed by the careful placing of 
Peel, E. \& Ellis, S.J. (forthcoming, 2018) Ageing and Chronic Illness in Language and

Sexuality. In K. Hall \& R. Barrett (Eds.) The Oxford Handbook of Language and Sexuality.

Oxford: Oxford University Press.

clothes or bed sheets (Hinchliff and Gott 2016). This is not only ageist, but renders the ageing body literally an 'unwatchable' process (Coupland 2003).

Ageism, and the ageist language that accompanies it, is pervasive. It is manifest in the discursive representation of older people and sedimented in terms such as "elderspeak." For instance, Gerard Fealy and colleagues (2012), in their critical discourse analysis of Irish print media, found five subject positions in the texts, which constructed older people as: 'victims'; 'frail, infirm and vulnerable'; 'radicalised citizens'; 'deserving old' and 'undeserving old'. They argue that these limited available discourses collectively position older people outside the societal mainstream because of their implicit othering and dependency (Fealy et al., 2012). There is also lineage of research focusing on the discursive and linguistic manifestations of ageism in various institutional settings, such as doctor-patient interaction (e.g., Greene, et al., 1986), intergenerational communication (e.g., Williams and Nussbaum 2012), and narratives and autobiographical stories produced by older people (Feldman 1999). To our knowledge, however, the communicative and linguistic intersecting contours of ageist, sexist, and heteronormative discourse have not yet been thoroughly mapped, a point to which we return in the conclusion.

Ageist in orientation, the discourse of the asexual older person is propped up by the proliferation of information about physiological changes to the body associated with ageing (Phillips and Marks 2008; Potts et al. 2006). The widespread highlighting of changes such as reduced libido, the inability to have and maintain erections (in men), and post-menopausal difficulties with arousal and lubrication (in women) construct sexual decline as an inevitable part of ageing. For example, one self-help guide on sexuality and ageing states that "there is much you can do to compensate for the normal changes that come with ageing [...] your latter years can be an exciting time to explore both the emotional and sensual aspects of your sexuality" (Block, Smith and Segal, 2016). Although this guidance is intended to be 
Peel, E. \& Ellis, S.J. (forthcoming, 2018) Ageing and Chronic Illness in Language and 10 Sexuality. In K. Hall \& R. Barrett (Eds.) The Oxford Handbook of Language and Sexuality. Oxford: Oxford University Press. supportive, it is framed in such a way as to present ageing as necessitating sexual compromise (indexed by the word "compensate") and qualitative change in sexual activity. It also orients to a mainstream heterosexist view of sexuality by implying the giving up of sex per se (i.e., intercourse) and settling for so-called 'soft' forms of sex (i.e., emotional intimacy, sensuality). This is then reified in research among older groups that definitively suggests that what counts as sexual fulfilment changes over the life course, with less emphasis on intercourse and more on intimacy and connectedness (e.g., Sandberg 2013; Arrington 2000).

In direct contrast with this discourse of decline, publicly available health information normalizes sexuality in old age, situating it within a social climate of 'healthy ageing'. For example, online health sources feature information such as "intimacy and connection are just as important later in life as they are earlier" (Rogers 2016) and “sex doesn't automatically stop once a person gets their free bus pass" (NHS Choices 2015). Within this paradigm, sexuality is constructed as a natural and necessary component for healthy or positive ageing (Sandberg 2013; Schrerrer 2009). This cultural shift has given rise to the idea that despite physiological decline, ageing bodies can be medically (re-)enabled to restore sexual performance (Phillips and Marks 2008; Schrerrer 2009). Overwhelmingly, this medicalization of sexuality and ageing has focused on 're-sexing' the ageing male body (e.g., Slevin and Linneman 2010), including little or no discussion of sexuality and ageing as it applies to women. However, even for men the focus solely on 'erectile dysfunction' and the promotion of pharmaceutical solutions such as Viagra perpetuates a sense of abnormality and inadequacy rather than increased opportunities for intimacy and experimentation (Potts et al. 2006). This biomedical approach to ageing and sexuality is equally problematic in its orientation to gender normativity, essentially reinscribing a gender binary that renders transgender bodies invisible (Brown 2009). 
Peel, E. \& Ellis, S.J. (forthcoming, 2018) Ageing and Chronic Illness in Language and 11 Sexuality. In K. Hall \& R. Barrett (Eds.) The Oxford Handbook of Language and Sexuality. Oxford: Oxford University Press.

As well as being gender-biased, discourses around sexuality and ageing are also heavily reductionist. Founded on a heterosexist, biomedical model of bodies and sexual experiences, they narrowly construct sexuality as being solely about genital function (Potts et al. 2006), ignoring the complex interplay between mind and body. This focus on 'function' and 'performance' is particularly problematic for those living with chronic illness or degenerative diseases which may impact on an individual's ability to be (and remain) sexually fulfilled as they age. For some, physical health issues unrelated to genital function (e.g., pain from illness, limited physical strength, negative effects of medication) will undoubtedly impact on their ability to engage in some forms of sexual activity, but will not necessarily inhibit sexual desire or needs. Conversely, conditions affecting brain function such as Alzheimer's disease will undoubtedly affect a person's ability to articulate their sexual desires, but will not necessarily mean that they cannot experience sexual intimacy. Therefore, discourses around sexuality and ageing orient to an able-bodied understanding of sexuality that acts to marginalize those experiencing chronic illness (see also Ramanathan this volume).

Through their construction within a heteronormative framework, dominant discourses of ageing have also rendered invisible the ageing experiences of LGBT people. While in part this is due to heavily heterocentric language in medical discourse around sexuality and ageing, it is also partly attributable to marked cohort differences in visibility of, and language around, same sex orientation and non-heterosexual relationships (see footnote 1). Having experienced a lifetime of stigmatization, many older LGBT people find themselves engaging in complex identity work in order to define their own sexuality and to negotiate when it is 'safe' to disclose (cf. Phillips and Marks 2008; Rosenfeld 1999). Perhaps more poignantly though, the heteronormative framework within which much discourse around sexuality and ageing is situated has resulted in a rhetorical silence around LGBT ageing, which is 
Peel, E. \& Ellis, S.J. (forthcoming, 2018) Ageing and Chronic Illness in Language and 12 Sexuality. In K. Hall \& R. Barrett (Eds.) The Oxford Handbook of Language and Sexuality. Oxford: Oxford University Press. perpetuated not just in the academic literature but also in human services practice (Brown 2009; Hossein 2016). For example, an analysis of advertising brochures for aged care facilities showed that non-heterosexual relationships were routinely missing from visual imagery and verbal texts; and when "diversity" was mentioned, it related specifically to racial/ethnic groups with no reference to sexual minorities (see Phillips and Marks 2008). While work on rhetorical silence in relation to LGBT ageing has been largely theoretical (e.g., see Brown 2009; Hossein 2016), language based analyses can be useful in better understanding the impact of this silencing on the lived experiences of LGBT persons as they age.

The ways in which sexual identities are claimable — that is, the ways speakers use language to communicate and understand their sexuality — is highly contingent on social context. The languages deployed by different LGBTQ groups, as distinct from examination of metaphor and discourse, has been another key focus in language and sexuality research. When sub-cultural languages and linguistic registers are viewed through an ageing lens then generational distinctiveness becomes important. The 'cohort effects' (i.e. age group differences) with regard to language registers associated with sexual identities can be marked, with older cohorts of LGBTQ people using registers which may not be fully intelligible to young generations, for example. Polari, a slang language developed and used by gay men in the decades prior to sex between men being decriminalized in Britain, was essentially "a collection of words and phrases that could be strategically employed either to create a sense of belonging ... or to exclude naff omees [straight men] from pointed conversation" (Lucas, 1999: 87). The sub-cultural language of Polari is a good illustration of how particular linguistic practices are associated with a particular generational cohort (Baker, 2002), and strongly linked in place and time. ${ }^{3}$ Older gay men (and the broader ageing LGBT community) may have a connection to these kinds of registers and linguistic patterns in terms 
Peel, E. \& Ellis, S.J. (forthcoming, 2018) Ageing and Chronic Illness in Language and 13 Sexuality. In K. Hall \& R. Barrett (Eds.) The Oxford Handbook of Language and Sexuality. Oxford: Oxford University Press. of forming and understanding identities. By the same token, these groups may, for example, be less accepting of the reclaimed term 'queer' more common among younger LGBT people (Jones 2016). In researching sexuality and ageing it is therefore important to understand, and address, differences that may be age cohort specific.

A longitudinal, life course perspective can be particularly fruitful when considering contextual variation in the construction, maintenance, and transformation in sexual identities through the process of ageing, a process that is typically impacted by the development and integration (or self-management, to use another phrase) of single or multiple chronic illnesses. Rebecca Jones (2016) uses the example of bisexuality to argue that research about non-heterosexual ageing should attend more closely to how sexual identity labels are used over the life course. Bisexuality may be foregrounded more firmly in a longitudinal lens than when discussed at particular moments in the past, present, or future, where it may be differently understood or even decried:

Life review in the context of an awareness of finitude, perhaps after the death of a longterm partner or around retirement, may cause people to reconfigure their past history (Ruth, Birren, and Polkinghorne 1996). This reconfiguring might have a variety of results in terms of sexual identities, one of which might be to make the label of bisexuality seem personally applicable in a new way. (Jones 2016: 98)

Therefore, researchers may gain mileage in charting the identity categories and language deployed by older LGBT people through the life course. This notion has been furthered in Andrew King's (2016) analysis of older LGB people's talk using the membership categorization analysis (MCA) component of conversation analysis. Drawing on the work of Harvey Sacks (1995) and Elizabeth Stokoe (2004), King argues that “older LGB people’s 
Peel, E. \& Ellis, S.J. (forthcoming, 2018) Ageing and Chronic Illness in Language and 14 Sexuality. In K. Hall \& R. Barrett (Eds.) The Oxford Handbook of Language and Sexuality. Oxford: Oxford University Press. identities should not be treated as a priori entities, but as performative and discursively constructed, argued over and rejected within interactions" (2016: 169). King highlights how the membership categorization devices associated with 'sexuality' are both made relevant in his interview interactions and troubled by his interviewees. When sexual identity is made relevant to the interaction, certain categories are brought into play because sexuality is an accountable identity: typically, speakers use a socially recognizable category (e.g., bisexual), then offer a clarification of how they fit or distance themselves from that category. For example, a speaker may use the category lesbian and then explain, "we really don't label ourselves do we" (p. 171). In this research, much of the troubling of sexual identity categories was occasioned by the question - starting with an extreme case formulation - "We all use different terms to describe our sexuality (.) so it would be helpful for me if you could tell me how you describe your sexual identity" (King 2016: 172). One participant, Ernest, distances himself from the category gay in the passage quoted below when outlining what he links to a gay identity. This discourse strategy is in keeping with understandings of 'passing' among older lesbians and gay men, who often experienced social contexts where non-heterosexuality was more socially proscribed.

I've never lived erm (.) I've always been around other gay people but I've never lived in an exclusively gay community I've never been in an exclusively gay relationship although I've had quite a few fairly long-term gay relationships (.) but er (.) I wouldn't consider anything like a civil partnership or anything in a formalised way (.) I have been married but that was purely for erm immigration purposes while I lived briefly in America (0.3) and that didn’t succeed at all hehhehh (0.5) it wasn't a very rewarding experience (Ernest, quoted in King 2016: 173) 
Peel, E. \& Ellis, S.J. (forthcoming, 2018) Ageing and Chronic Illness in Language and 15 Sexuality. In K. Hall \& R. Barrett (Eds.) The Oxford Handbook of Language and Sexuality. Oxford: Oxford University Press. Similarly, King (2016) illustrates that when categories of age were made relevant, the participants did not want to be considered 'past it', and tended to reject the category old or older. Therefore, as King and others have highlighted, discourses associated with ageing and sexuality are far more nuanced and troubled than either a 'successful ageing' or a 'sexy oldie' narrative might suggest. Identifying someone as an older lesbian, gay, or bisexual person is not straightforward: it involves complex identity categorization work, played out through the performative use of identity categories and their associated attributes within interactions.

\section{SEXUALITY AND CHRONIC ILLNESS}

There are numerous and complex ways in which context, labelling, identities, sexuality and chronic illness intersect. If we take the example of sexuality in older people living with dementia in a residential care context, the person themselves may communicate a healthy and active sexuality (either verbally or non-verbally), but this may be interpreted by staff or families as 'inappropriate': “[t]he older person can then become constructed as 'difficult' or 'challenging', and this construction is harmful' (Bauer, McAuliffe, and Fetherstonhaugh 2016: 121). Similarly, older people with dementia engaging in regular walking could be discursively framed positively by residential institutions as contributing towards what is widely consider to be the "best buy in public health" (Morris 1994, quoted in Peel, Douglas, Parry, and Lawton 2010: 570), namely moderate physical activity. But walking in this context is far more likely to be constructed as problematic "wandering." As Bauer and colleagues (2016) note with respect to sexual activity, and indeed as we also see in the communication and presentation of sexual and gendered identity (Peel and McDaid 2015): “[t]here is much disagreement about the 'now' self vs the 'then' self and which should take priority in decisions around best interests and the person with dementia" (Bauer et al. 2016: 128). We can see here that communicative approaches in ageing sexuality, as well as their reception 
Peel, E. \& Ellis, S.J. (forthcoming, 2018) Ageing and Chronic Illness in Language and 16 Sexuality. In K. Hall \& R. Barrett (Eds.) The Oxford Handbook of Language and Sexuality. Oxford: Oxford University Press. and interpretation, have much to offer language scholars, as does the discursive production of sexual and gendered identity categories in the context of ageing and chronic illness.

We now turn to the gendered construction of dietary self-management in the context of type 2 diabetes, a chronic illness which typically affects people over the age of forty. Peel, Parry, Douglas and Lawton's (2005) study adopted a discursive psychological approach to talk about health behavior, focusing specifically on the actions being accomplished in interview talk about non-adherence to the dietary aspect of diabetic self-management regimen with a sample $(n=40)$ of those newly diagnosed in Scotland. In this study, the researchers found that older heterosexual women living with type 2 diabetes tended to construct managing their diet as an individual concern, while heterosexual male participants discursively produced their diet as a family matter. Likewise, when older people with diabetes accounted for lapses in prescribed diet, they did so in ways that maximized a positive identity for their respective genders. For instance, 'cheating' was constructed divergently by women and men as either contextually bounded (e.g., "when my menstrual cycle's coming up [...] but er (.) apart from that, been pretty good"; Ellen, quoted in Peel et al., 2005: 786) or as permitted by health professionals (e.g., "the doctors (.) have told me '[unclear] erm 'a couple of squares of chocolate is okay',"; Callum, quoted in Peel et al., 2005: 787).

The analysis that is now discussed, drawing on interview data with Sandra - a 41 year old heterosexual women - and David - a 58 year old heterosexual man - neatly illustrates a divergent heteronormatively gendered construction of dietary self-management in diabetes. Sandra's account stresses prioritizing the needs of the family while David's is focused on having his dietary needs met by his wife. In the extract below from Sandra, the theoretical possibility (“could") of buying healthy food (in this case, white meat) and cooking it in a 
Peel, E. \& Ellis, S.J. (forthcoming, 2018) Ageing and Chronic Illness in Language and 17 Sexuality. In K. Hall \& R. Barrett (Eds.) The Oxford Handbook of Language and Sexuality. Oxford: Oxford University Press. healthy way ("grill[ing]" as opposed to frying) is contrasted with the 'realities' of family life. Sandra posits that her daughter Amy would definitively "not eat that":

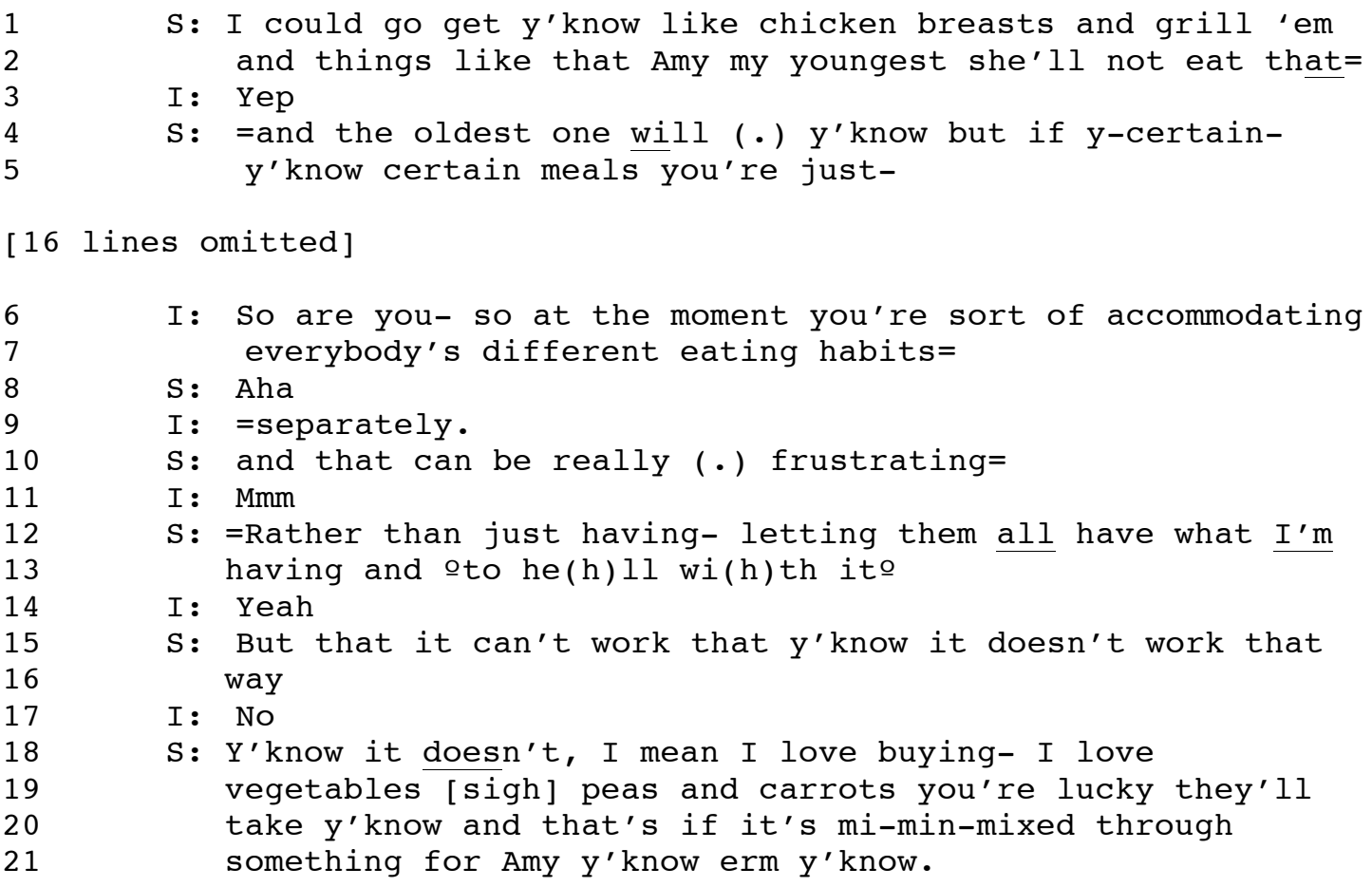

(from Peel et al. 2005: 783)

Sandra agrees with the interviewer's summary that she's accommodating her family's eating habits rather than focusing on her own in line 8 , and then offers an assessment and extension of it in line 10 ("and that can be really (.) frustrating"). In lines 15 and 16, she reinforces the heteronormative immutability of her domestic situation three times over (“"it can't work"”; “"it doesn't work"”; ““it doesn't”'), while also attending to what constitutes being a "good mother", signalled through the interpolated laughter particles in line 13.

In contrast, David, another participant in the study, emphasizes how unproblematic the management of his diet is for himself ("I don't have a problem..." in lines 1-2, 4, and 8):

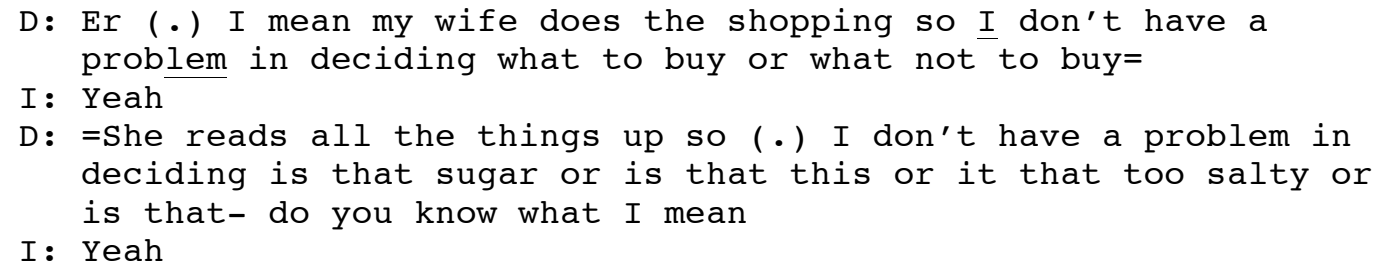


Peel, E. \& Ellis, S.J. (forthcoming, 2018) Ageing and Chronic Illness in Language and 18 Sexuality. In K. Hall \& R. Barrett (Eds.) The Oxford Handbook of Language and Sexuality. Oxford: Oxford University Press.

(from Peel et al. 2005: 785)

Although David's account is also heteronormative, he distances himself from what he views as the difficult activity of appropriate food selection by claiming that his dietary needs are managed by his wife in such a way that they do not impinge on his relationship with food, shielding him from the disappointment that this would potentially entail (lines 8-9). At the same time, David distances himself from an identity shaped by (or perhaps controlled by) the demands of diabetes.

Scant social science research on type 2 diabetes self-management and its impact on identity has been conducted outside a heteronormative frame. Thus we turn our attention briefly now to the discursive production of non-heterosexual sexual identities in the context of diabetes. In contrast to what was found in the heternormatively gendered research described above, accounts produced by gay and bisexual men in a different study conducted in England cohered around talk about sexual function, and the impact of the condition on intimacy and sexual behaviour (Jowett, Peel, and Shaw 2011). For instance, Colin, a 62 year old gay men who had lived with type 1 diabetes for 40 years, described the deleterious effects of erectile dysfunction:

[Impotence] had over the years killed my social life ...[...] I remember on one occasion I went into a gay pub and there was a lad I'd been eyeing up for months, stunning from my point of view and erm...next thing I knew he was standing next to me. [...] I was too frightened because I wouldn't want somebody on our local scene to know that erm, I couldn't rise to the occasion. And that's the one problem with gay life ...in heterosexuality, you meet on another occasion and you go out and you go for dinner or 
Peel, E. \& Ellis, S.J. (forthcoming, 2018) Ageing and Chronic Illness in Language and 19 Sexuality. In K. Hall \& R. Barrett (Eds.) The Oxford Handbook of Language and Sexuality. Oxford: Oxford University Press. for whatever and you chat to them. It's a long time before you actually got into bed, but the gay life was never like that, that was almost always the first time you meet. So that was terrifying me I couldn't do it. (Jowett, Peel, and Shaw 2012: 412)

In Colin's account, the wide reaching significance of impotence ("killed my social life") is contextually heightened by what he constructs as "the one problem with gay life" - the imperative to have sex quickly (though he later historicizes this semantically extreme case formulation as typically limited to "almost always the first time you meet.") By contrasting subcultural norms of 'gay life' with sedate 'heterosexuality', and by conveying the negative emotion ("frightened,", "terrifying") associated with the insularity and implicit hegemonic masculinity of "our local scene," Colin constructs this secondary complication from diabetes as significantly impacting on his identity. Similarly, Enzo, a 47 year old with type 2 diabetes, constructed his inability to masturbate ("the mechanics don't work") as the answer to his rhetorical question "is there anything you resent about diabetes?," implicitly underscoring the importance of impotence in the production of gay male diabetic identities (Jowett, Peel and Shaw, 2012: 413). This discussion of sexuality and chronic illness has highlighted that in some (largely heternormative) ageing contexts, sexuality is disappeared in discourse, and in others (such as gay and bisexual men with diabetes) sexuality is fundamentally salient.

\section{CONCLUDING REMARKS}

In this chapter we have offered a review of the state of knowledge regarding discourse and sexuality when applied to ageing and chronic illness. We focused particularly on discursive research from across the social sciences that has enabled understandings of older people's lives and experiences. We highlighted research that has focused on ageism and common chronic conditions that impact older people, namely dementia and type 2 diabetes. We have 
Peel, E. \& Ellis, S.J. (forthcoming, 2018) Ageing and Chronic Illness in Language and 20 Sexuality. In K. Hall \& R. Barrett (Eds.) The Oxford Handbook of Language and Sexuality. Oxford: Oxford University Press. also explored the interface between sexuality and ageing, discussing the ways in which competing discourses of 'sexual decline' and 'healthy (sexual) ageing' contribute to the marginalization and invisibility of both LGBT people and those experiencing chronic illness. Our discussion has, to some extent, shown how language-based approaches are helpful for understanding the ways in which notions such as 'sexual decline' are fundamentally ageist and those around 'healthy (sexual) ageing' orient to an able-bodied understanding of ageing.

In conclusion, we suggest that the intersection of language, sexuality, ageing, and chronic illness could develop into an important aspect of language and sexuality scholarship. One approach that could be usefully deployed in this regard is conversation analysis (see Stokoe and Speer this volume). King's (2016) membership categorization analysis (MCA) of older LGB people's interview talk, which we previously discussed, offers one avenue to interrogate how different identity categories are claimed, resisted, and negotiated, but there is potentially much to be gained as well through sequential analysis of talk-in-interaction (e.g., the communication of dementia diagnosis; see Peel 2015). CA informed analyses of either mundane or institutional talk offer an especially rich vein for those interested in the everyday seams and folds of social interaction - a vein that can likely be mined for the production and critique of ageist, heterosexist, sexist, and disablist talk.

To take one final example, Celia Kitzinger's (2005) persuasive analysis of the reproduction of heteronormativity in medical calls requesting a home visit shows how heterosexism can be iterated and reiterated in institutional interactions "where there is no sign of trouble" (496). If the multiple axes of oppression and marginalization we have highlighted with respect to older LGB people with chronic or degenerative illness are to be interrogated and challenged, then as Kitzinger suggests:

It maybe particularly important to target for analysis precisely those everyday interactions which seem unremarkable, where nothing special appears to be happening, 
Peel, E. \& Ellis, S.J. (forthcoming, 2018) Ageing and Chronic Illness in Language and 21 Sexuality. In K. Hall \& R. Barrett (Eds.) The Oxford Handbook of Language and Sexuality. Oxford: Oxford University Press. because what is always happening on such occasions is the reproduction of the normal, taken-for-granted world, invisible because it is too familiar. [...] In unravelling the social fabric of ordinary, everyday life, LGBT activists and researchers can make visible and challenge the mundane ways in which people - without deliberate intentreproduce a world that socially excludes or marginalizes non-heterosexuals. (Kitzinger 2005: 496)

Language and sexuality scholars are well placed to be able to analyse the subtle, often normative, linguistic and discursive ways in which non-heterosexuals are oppressed. As we have sought to demonstrate in this chapter, older people living with chronic and degenerative illness can be especially marginalized. And, therefore, we would wish to add older people, many of whom live with one or more chronic conditions, to Kitzinger's clarion call.

\section{ACKNOWLEDGMENTS}

With grateful thanks to the participants in the studies reported here, the British Academy for funding some of this research (Grants SG1000017 and MC110142), and Emma Preece for research assistance. Thanks also to collaborators on these various projects, namely Rosie Harding, Adam Jowett, Julia Lawton.

\section{NOTES}

1. Of course, older LGBTQ people occupy a distinctive historical location. The discursive reinvention of homosexuality means that some (especially those over the age of 65) formed their identities within a culture of stigmatization of homosexuality, while others 
Peel, E. \& Ellis, S.J. (forthcoming, 2018) Ageing and Chronic Illness in Language and 22 Sexuality. In K. Hall \& R. Barrett (Eds.) The Oxford Handbook of Language and Sexuality. Oxford: Oxford University Press. (i.e., those 50-65 years) formed their identities within a culture of gay liberation that topicalized homosexuality as a positive identity despite social stigma. These cohort effects result in differing orientations to the self as LGBTQ, to the extent of outness, and to how LGBTQ people want to live out their lives when older (Lyons et al. 2015; Rosenfeld 1999).

2. But see Loe (2004) and Beasley and Holmes (2016) for examples of research that counter the erasure of sexual desire in older heterosexual people, particularly women.

3. Polari was a slang language developed and used by gay men. It was derived from various influences including rhyming slang, Romany, Italian and Latin in the 19th century, and was popularised in the 1950s and 1960s by the characters Julian and Sandy (played by Kenneth Williams and Hugh Paddick) in the BBC radio series Round the Horne. The legacy of Polari existed more recently in the name of an older lesbian and gay organization, which ran in London from 1993-2009.

\section{REFERENCES}

Arrington, Michael I. 2000. Sexuality, society, and senior citizens: An analysis of sex talk among prostate cancer support group members. Sexuality and Culture, 4(4), 45-74.

Baker, Paul 2002. Polari - The lost language of gay men. London: Routledge.

Bauer, Michael, McAuliffe, Linda and Fetherstonhaugh, Deirdre. 2016. Older people and sexuality in residential aged care: Reconstructing normality. In Ageing and Sexualities: Interdisciplinary perspectives, eds. Elizabeth Peel and Rosie Harding, 119-140. London: Routledge.

Beasley, Chris and Holmes, Mary. 2016. Internet dating, sexual intimacy, and older people. In Ageing and Sexualities: Interdisciplinary perspectives, eds. Elizabeth Peel and Rosie Harding, 205-222. London: Routledge. 
Peel, E. \& Ellis, S.J. (forthcoming, 2018) Ageing and Chronic Illness in Language and 23 Sexuality. In K. Hall \& R. Barrett (Eds.) The Oxford Handbook of Language and Sexuality. Oxford: Oxford University Press.

Block, Jocelyn, Smith, Melinda and Segal, Jeanne. 2016. Better sex as you age: Tips for enjoying a healthy sex life as you get older. Helpguide.org. Available at http://www.helpguide.org/articles/aging-well/better-sex-as-you-age.htm Accessed $10 / 02 / 17$

Brown, Maria T. 2009. LGBT aging and rhetorical silence. Sexuality Research \& Social Policy, 6:4, 65-78.

Clarke, Victoria, Ellis, Sonja J., Peel, Elizabeth and Riggs, Damien W. 2010. Lesbian, Gay, Bisexual, Trans and Queer Psychology: An introduction. Cambridge: Cambridge University Press.

Coupland, Justine. 2003. Ageist ideology and discourses of control in skincare product marketing. In Discourse, the Body and Identity, eds. Justine Coupland and Richard Gwyn, 127-150. Basingstoke: Palgrave Macmillan.

Demjen, Zsofia, Semino, Elena, and Koller, Veronika. 2016. Metaphors for 'good' and 'bad' deaths: a health professional view. Metaphor and the Social World, 6:1, 1-19.

Department of Health 2001. National Service Framework: Older People. Available at: https://www.gov.uk/government/uploads/system/uploads/attachment_data/file/198033/N ational_Service_Framework_for_Older_People.pdf Accessed: 10/02/17

De Vries, Brian. 2007. LGBT couples in later life: A study in diversity. Generations, 31, 1823.

Erol, Rosie, Brooker, Dawn and Peel, Elizabeth. 2015. Women and Dementia: A global research review. London: Alzheimer's Disease International. Available at: http://www.alz.co.uk/women-and-dementia Accessed: 18/01/16 
Peel, E. \& Ellis, S.J. (forthcoming, 2018) Ageing and Chronic Illness in Language and 24 Sexuality. In K. Hall \& R. Barrett (Eds.) The Oxford Handbook of Language and Sexuality. Oxford: Oxford University Press.

Erol, Rosie, Brooker, Dawn and Peel, Elizabeth. 2016. The impact of dementia on women internationally: An integrative review. Health Care for Women International, 37(12), $1320-1341$.

Fealy, Gerard, McNamara, Martin, Treacy, Margaret P. and Lyons, Imogen. 2012.

Constructing ageing and age identities: a case study of newspaper discourses. Ageing and Society, 32:1, 85-102.

Feldman, Susan. 1999. Please don't call me 'dear': older women's narratives of health care. Nursing Inquiry, 6, 269-276.

Greene, Michele G., Adelman, Ronald, Charon, Rita and Hoffman, Susie. 1986. Ageing in the medical encounter: An exploratory study of the doctor-elderly patient relationship. Language \& Communication, 6:1-2, 113-124.

Jones, Rebecca L. 2016. Sexual identity labels and their implications in later life: The case of bisexuality. In Ageing and Sexualities: Interdisciplinary perspectives, eds. Elizabeth Peel and Rosie Harding, 97-118. London: Routledge.

Harvey, Keith. 2002. Camp talk and citationality: A queer take on 'authentic' and 'represented' utterance. Journal of Pragmatics, 34, 1145-1165.

Hinchliff, Sharron and Gott, Merryn. 2016. Ageing and sexuality in western societies: Changing perspectives on sexual activity, sexual expression and the 'sexy' older body. In Ageing and Sexualities: Interdisciplinary perspectives, eds. Elizabeth Peel and Rosie Harding, 11-31. London: Routledge.

Hossein, Kia. 2016. Hypervisibility: Toward a conceptualization of LGBTQ aging. Sexuality Research and Social Policy, 13:1, 46-57.

Jowett, Adam and Peel, Elizabeth. 2009. Chronic illness in non-heterosexual contexts: An online survey of experiences. Feminism \& Psychology, 19:4, 454-474. 
Peel, E. \& Ellis, S.J. (forthcoming, 2018) Ageing and Chronic Illness in Language and 25 Sexuality. In K. Hall \& R. Barrett (Eds.) The Oxford Handbook of Language and Sexuality. Oxford: Oxford University Press. Jowett, Adam, Peel, Elizabeth and Shaw, Rachel L. 2012. Sex and diabetes: A thematic analysis of gay and bisexual men's accounts. Journal of Health Psychology, 17:3, 409418.

King, Andrew. 2016. Troubling identities? Examining older lesbian, gay and/or bisexual people's membership categorisation work and its significance. In Ageing and Sexualities: Interdisciplinary perspectives, eds. Elizabeth Peel and Rosie Harding, 163-181. London: Routledge.

Kitzinger, Celia. 2005. Heteronormativity in action: Reproducing the heterosexual nuclear family in 'after hours' medical calls. Social Problems, 52:4, 477-498.

Knocker, Sally. 2013. Perspectives on Ageing Lesbians, Gay Men and Bisexuals. London: Joseph Rowntree Foundation.

Kulick, Don. 2000. Gay and lesbian language. Annual Review of Anthropology, 29, 243-285. Lackoff, George and Johnson, Mark. 2003. Metaphors we Live By. Chicago: University of Chicago Press.

Lane, Heather P., McLachlan, SueAnne and Philip, Jennifer. 2013. The war against dementia: Are we battle weary yet? Age and Ageing, 42, 281-283.

Lee, David M., Nazroo, James, O'Connor, Daryl B., Blake, Margaret and Pendleton, Neil. 2016. Sexual Health and Well-being Among Older Men and Women in England: Findings from the English Longitudinal Study of Ageing. Archives of Sexual Behavior, $45: 1,133-144$.

Loe, Meika 2004. Sex and the senior woman: Pleasure and danger in the Viagra era. Sexualities, 7(3), 303-326.

Lucas, Ian. 1997. The colour of his eyes: Polari and the sisters of perpetual indulgence. In A. Livia \& K. Hall (Eds.), Queerly phrased: Language, gender and sexuality (pp.85-94) New York: Oxford University Press. 
Peel, E. \& Ellis, S.J. (forthcoming, 2018) Ageing and Chronic Illness in Language and 26 Sexuality. In K. Hall \& R. Barrett (Eds.) The Oxford Handbook of Language and Sexuality. Oxford: Oxford University Press.

Lyons, A., Croy, S., Barrett, C. and Whyte, C. 2015. Growing old as a gay man: How life has changed for the gay liberation generation. Aging \& Society, 3, 2229-2250.

Marshall, Barbara L. 2006. The new virility: Viagra, male aging and sexual function. Sexualities, 9:3, 345-362.

NHS Choices 2015. A third of over-70s report 'frequent sexual activity'. Available at http://www.nhs.uk/news/2015/01January/Pages/A-third-of-over-70s-report-frequentsexual-activity.aspx Accessed: 28/01/16.

Peel, Elizabeth. 2014. 'The living death of Alzheimer's' versus 'Take a walk to keep dementia at bay': Representations of dementia in print media and carer discourse. Sociology of Health and Illness, 36:6, 885-901.

Peel, Elizabeth. 2015. Diagnostic communication in the memory clinic: A conversation analytic perspective. Aging \& Mental Health, 19:12, 1123-1130.

Peel, Elizabeth and Harding, Rosie. 2014. "It's a huge maze, the system, it's a terrible maze": Dementia carers' constructions of navigating health and social care services. Dementia: The International Journal of Social Research and Practice, 13:5, 642-666.

Peel, Elizabeth and Harding, Rosie. 2016. Eds. Ageing and Sexualities: Interdisciplinary perspectives. London: Routledge.

Peel, Elizabeth, Douglas, Margaret, Parry, Odette and Lawton, Julia. 2010. Type 2 diabetes and dog walking: Patients' longitudinal perspectives about implementing and sustaining physical activity. British Journal of General Practice, 60:577, 570-577.

Peel, Elizabeth, Parry, Odette, Douglas, Margaret and Lawton, Julia. 2005. Taking the biscuit? A discursive approach to managing diet in type 2 diabetes. Journal of Health Psychology. 10:6, 779-791.

Peel, Elizabeth and McDaid, Sam. 2015. 'Over the Rainbow': Lesbian, gay, bisexual, trans people and dementia project. Summary Report. University of Worcester. Available at: 
Peel, E. \& Ellis, S.J. (forthcoming, 2018) Ageing and Chronic Illness in Language and 27 Sexuality. In K. Hall \& R. Barrett (Eds.) The Oxford Handbook of Language and Sexuality. Oxford: Oxford University Press. http://dementiavoices.org.uk/wp-content/uploads/2015/03/Over-the-Rainbow-

LGBTDementia-Report.pdf Accessed: 10/02/17

Phillips, Joy and Marks, Genée. 2008. Ageing lesbians: Marginalising discourses and social exclusion in the aged care industry. Journal of Gay and Lesbian Social Services, 20:1/2, $31-49$.

Potts, Annie, Grace, Victoria M., Vares, Tina and Gavey, Nicola. 2006. 'Sex for life'? Men’s counter-stories on 'erectile dysfunction', male sexuality and ageing. Sociology of Health \& illness, 28:3, 306-329.

Rogers, Pamela. 2016. Sex and Aging. Healthline. Available at www.healthline.com/health/healthy-sex-and-aging\#overview1 Accessed 10/02/17

Rosenfeld, Dana. 1999. Identity work among lesbian and gay elderly. Journal of Aging Studies, 13:2, 121-144.

Ruth, Jan-Erik, Birren, James E. and Polkinghorne, Donald E. 1996. The projects of life reflected in autobiographies of old age. Ageing and Society, 16:6, 677-699.

Sandberg, Linn. 2013. Just feeling a naked body close to you: Men, sexuality and intimacy in later life. Sexualities, 16:3/4, 261-282.

Sacks, Harvey. 1995. Lectures on Conversation: Volumes 1\&2, Oxford: Blackwell.

Scherrer, Kristin S. 2009. Images of sexuality and aging in gerontological literature. Sexuality Research and Social Policy, 6:4, 5-12.

Semlyen, Joanna, Brooke, Joanne and Peel, Elizabeth. submitted. The needs of lesbian, gay, bisexual and trans (LGBT) people who are affected by dementia: A comprehensive scoping review. Dementia: The International Journal of Social Research and Practice.

Slevin, Kathleen F. and Linneman, Thomas J. 2010. Old gay men's bodies and masculinities. Men and Masculinities, 12:4, 483-507.

Sontag, Susan. 1978. Illness as Metaphor. New York: Farrar, Straus and Giroux. 
Peel, E. \& Ellis, S.J. (forthcoming, 2018) Ageing and Chronic Illness in Language and 28 Sexuality. In K. Hall \& R. Barrett (Eds.) The Oxford Handbook of Language and Sexuality. Oxford: Oxford University Press.

Stokoe, Elizabeth H. 2004. Gender and Discourse, Gender and Categorization: Current

Developments in Language and Gender Research. Qualitative Research in Psychology 1, 107-129.

Sutherland, Mike, Rivers, Ian and Ward, Richard. 2012. Introduction: Lesbian, gay, bisexual, and transgender ageing: providing effective support through biographical practice. In Lesbian, gay, bisexual, and transgender ageing: Biographical approaches for inclusive care and support, eds. Richard Ward, Ian Rivers and Mike Sutherland, 9-17. London: Jessica Kingsley.

Tyler, Allan, Nodin, Nuno, Peel, Elizabeth and Rivers, Ian. 2016. "I am getting old and that takes some getting used to": Dimensions of body image for older men. In Ageing and Sexualities: Interdisciplinary perspectives, eds. Elizabeth Peel and Rosie Harding, 141162. London: Routledge.

Ward, Richard, Vass, Antony A., Aggarwal, Neeru, Garfield, Cydonie and Cybyk, Beau. 2005. A kiss is still a kiss? The construction of sexuality in dementia care. Dementia, $4: 1,49-72$.

Westwood, Sue. 2014. Dementia, women and sexuality: How the intersection of ageing, gender and sexuality magnify dementia concerns among lesbian and bisexual women. Dementia: The International Journal of Social Research and Practice. Advance access.

Williams, Angie and Nussbaum, Jon F. 2012. Intergenerational Communication Across the Lifespan. New York: Routledge.

World Health Organisation (WHO) 2015. World Report on Ageing and Health. Geneva: WHO. Available at: http://apps.who.int/iris/bitstream/10665/186463/1/9789240694811_eng.pdf Accessed $18 / 01 / 16$ 